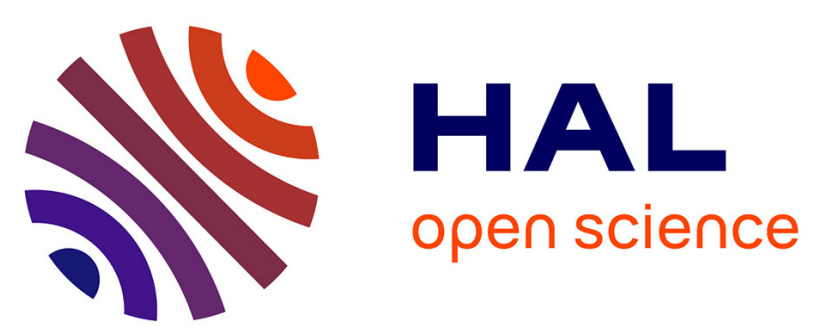

\title{
Effect of rhodium doping on the photorefractive properties of BCT crystals at $850 \mathrm{~nm}$
}

Sylvie Bernhardt, H. Veenhuis, Philippe Delaye, R. Pankrath, Gérald Roosen

\section{To cite this version:}

Sylvie Bernhardt, H. Veenhuis, Philippe Delaye, R. Pankrath, Gérald Roosen. Effect of rhodium doping on the photorefractive properties of BCT crystals at 850nm. Applied Physics B - Laser and Optics, 2001, 72, pp.667-675. 10.1007/s003400100574 . hal-00674648v2

\section{HAL Id: hal-00674648 \\ https://hal-iogs.archives-ouvertes.fr/hal-00674648v2}

Submitted on 30 Mar 2012

HAL is a multi-disciplinary open access archive for the deposit and dissemination of scientific research documents, whether they are published or not. The documents may come from teaching and research institutions in France or abroad, or from public or private research centers.
L'archive ouverte pluridisciplinaire HAL, est destinée au dépôt et à la diffusion de documents scientifiques de niveau recherche, publiés ou non, émanant des établissements d'enseignement et de recherche français ou étrangers, des laboratoires publics ou privés. 


\title{
Effect of rhodium doping on the photorefractive properties of BCT crystals at $850 \mathrm{~nm}$
}

\author{
S.Bernhardt ${ }^{(1)}$, H.Veenhuis ${ }^{(2)}$, P.Delaye ${ }^{(1)}$, R.Pankrath $^{(2)}$, G.Roosen ${ }^{(1)}$ \\ (1) Laboratoire Charles Fabry de l'Institut d'Optique , Unité Mixte de Recherche 8501 du Centre National de la \\ Recherche Scientifique, Bat. 503, Centre Scientifique d'Orsay, B.P. 147, 91403 Orsay Cedex, France. \\ (2) Universität Osnabrück, FachBereich Physik, D 49069 Osnabrück, Germany
}

Corresponding Author : Ph. Delaye, Tel : 331 69358750, Fax : 331 69358700, Email :

Philippe.delaye@iota.u-psud.fr

\begin{abstract}
We present an experimental investigation of the photorefractive properties of rhodium doped barium calcium titanate crystals of the congruently melting composition $\mathrm{Ba}_{0.77} \mathrm{Ca}_{0.23} \mathrm{TiO}_{3}$. Considering the results previously obtained on this crystal in the visible region, it should be a good alternative to $\mathrm{BaTiO}_{3}$. Nevertheless, many applications use infrared light. Therefore we present here a study of rhodium doped BCT crystals at $850 \mathrm{~nm}$. This wavelength is of special interest as it is in the spectral range of laser diodes. Rhodium doping is expected to enhance the sensitivity of the crystal in the infrared as it is the case for $\mathrm{BaTiO}_{3}$.

We first noticed that BCT:Rh crystals are sensitive at this wavelength as expected. Furthermore, the photorefractive properties are interesting in term of photorefractive gain, with a gain as high as $3 \mathrm{~cm}^{-1}$ with ordinary polarization. This study has also put forward the fact that rhodium is not the only defect that participates in the photorefractive effect. Indeed, a large quantity of iron seems to be present in the BCT crystals and to participate in the photorefractive effect.
\end{abstract}

PACS : 42.65 Hw, 77.84 S 
It has been demonstrated that rhodium improves the infrared sensitivity of $\mathrm{BaTiO}_{3}$ so that the crystal is of special interest for many applications. It exhibits high photorefractive gain, small response time and its behaviour is well explained with a two-level model with three states of charges of rhodium : $\mathrm{Rh}^{3+}, \mathrm{Rh}^{4+}$ and $\mathrm{Rh}^{5+}[1,2]$. But it suffers from a drawback that prevents its use in industrial systems : a phase transition around $5^{\circ} \mathrm{C}$, that can destroy it .

Recently, first results about a new ferroelectric crystal derived from $\mathrm{BaTiO}_{3}$ with no phase transition at room temperature, $\mathrm{Ba}_{0.77} \mathrm{Ca}_{0.23} \mathrm{TiO}_{3}$, were published and show that this crystal has high electrooptic coefficients and high gain in the visible region [3--5]. As BCT is close to $\mathrm{BaTiO}_{3}$, it is expected that rhodium will also improve the sensitivity of BCT in the infrared. BCT:Rh may thus be an alternative to $\mathrm{BaTiO}_{3}: \mathrm{Rh}$, provided its photorefractive properties in terms of response time, photorefractive gain and saturation intensity are good enough. Therefore, we will focus in this paper on the photorefractive properties of this new material at the near infrared wavelength $850 \mathrm{~nm}$. Absorption and two-beam coupling gain measurements are carried out in order to find out whether rhodium doping improves the photorefractive performances of BCT in the infrared.

\section{EXPERIMENTAL RESULTS}

\subsection{Crystals}

BCT crystals grown with 0, 220, 370, 600, 1000 and 2000 ppm of rhodium added in the melt and one crystal with $140 \mathrm{ppm}$ of iron are studied. Typical dimensions are $2 * 3 * 4(=\mathrm{c}) \mathrm{mm}^{3}$.

The absorption spectra are presented in Fig.1 (except for the $600 \mathrm{ppm}$ rhodium doped crystal for which the absorption spectrum was not measured). The influence of rhodium on absorption is the same as in $\mathrm{BaTiO}_{3}: \mathrm{Rh}$ with a large absorption band around $600 \mathrm{~nm}$ which was attributed to this dopant $[5,6]$. We can note in Fig.1 that the absorption band seems to increase proportionnally to the amount of rhodium added in the melt. To confirm this point, we normalized the absorption spectra to the quantity of rhodium added in the melt (Fig.2a). To improve this comparison, we first substrated the absorption contribution of the undoped crystal from the ones of the rhodium doped samples as we consider the absorption of the undoped BCT as a residual absorption present in all crystals. A departure from this assumption can explain the discrepancy between the curves in the short wavelength part of the spectrum (400-600 mn). In the upper part of the spectrum, the low amplitude of the absorption background leads to a minor influence of the assumption except for crystals containing small amount of rhodium (like the $200 \mathrm{ppm}$ rhodium doped crystal for which the calculation is not performed). The similarity of the normalized absorption curves leads us to the conclusion that the observed absorption band is proportionnal to the rhodium doping.

Moreover, we also see that the absorption spectra for the undoped and iron doped crystals are similar. Indeed, as shown by Fig.2b, both spectra are proportionnal, which certainly indicates the presence of iron in the undoped crystal.

\subsection{Two beam coupling experimental procedure}


We carried out measurements of the photorefractive gain by using the two beam coupling experimental arrangement shown in Fig.3. Two coherent beams issued from a DBR laser diode at 850 $\mathrm{nm}$ were aligned so that the direction of the grating wave vector made an angle $\beta$ with the c-axis of the crystal. All the experiments (with the exception of the measurement of $r_{42}^{T}$ ) are performed with ordinary polarizations and with symmetric incidences of the beams $(\beta=0)$. The choice of the ordinary polarization enables us to measure moderate energy transfers and thus prevents us from any measurement problems due to depletion of the pump beam, beam fanning or oscillation of beams inside the crystal that often occurs with extraordinary polarizations. The signal beam diameter was reduced compared to the one of the pump beam by passing through a hole $\mathrm{H}$ to ensure a good overlap between the two beams. Furthermore, the intensity of the signal beam was much less than the one of the pump beam (a factor of 100) in order to be in the undepleted pump approximation. From the steady state intensities of the transmitted signal beam without $\left(\mathrm{I}_{\mathrm{S}}\right)$ and with $\left(\mathrm{I}_{\mathrm{SP}}\right)$ illumination by the pump beam, we calculated the two beam coupling coefficient $\Gamma$ according to Eq. 1 :

$\Gamma=\frac{1}{1} \ln \left(\frac{\mathrm{I}_{\mathrm{SP}}}{\mathrm{I}_{\mathrm{S}}}\right)$

where 1 is the length of interaction between the two beams, which corresponds here to the length of the crystal. Each measurement datum corresponds to a measurement in attenuation and in amplification allowing to separate the photorefractive components from an eventual absorption contribution (induced absorption or absorption grating). We measured the dependence of the gain with several parameters : intensity of the pump beam, grating wave vector, angle between the c-axis and the grating wave vector $\beta$.

\subsection{Theoretical aspect}

The dependence of the gain with the grating wave vector $\mathrm{k}_{\mathrm{r}}$ and with intensity I can be most of the time described by a general expression of the form $[7,8,9,10]$ :

$$
\Gamma=\frac{2 \pi}{\lambda_{0}} \mathrm{n}^{3} \frac{\mathrm{k}_{\mathrm{B}} \mathrm{T}}{\mathrm{e}} \mathrm{r}^{\text {eff }} \eta(\mathrm{I}) \frac{\mathrm{k}_{\mathrm{r}}}{1+\frac{\mathrm{k}_{\mathrm{r}}^{2}}{\mathrm{k}_{0}^{2}(\mathrm{I})}}
$$

where $\lambda_{0}$ is the wavelength of light in vacuum, $n$ the mean refractive index and $r^{\text {eff }}$ the effective electrooptic coefficient.

In this expression, $\eta(I)$ expresses the saturation of the gain with intensity which generally writes as :

$$
\eta(I)=\frac{1}{1+\frac{I_{\text {sat }}}{I}}
$$


and $\mathrm{k}_{\mathrm{o}}$ expresses as a function of the effective trap density $\mathrm{N}_{\text {eff }}$ according to (with the effective dielectric constant $\left.\varepsilon^{\text {eff }}(\beta)\right)$ :

$$
\mathrm{k}_{0}^{2}(\mathrm{I})=\frac{\mathrm{e}^{2} \mathrm{~N}_{\text {eff }}(\mathrm{I})}{\mathrm{k}_{\mathrm{B}} \mathrm{T} \varepsilon_{0} \varepsilon^{\text {eff }}(\beta)}
$$

On the one hand, the saturation of the gain is physically linked to the respective amplitudes of the photoconductivity and the dark conductivity, $\eta(\mathrm{I})$ going to one for illumination at which photoconductivity overpasses the dark conductivity. On the other hand, the intensity dependence of the effective trap density is due to the charge redistributions that can occur among different photorefractive species. Using these expressions (Eq. 1 to 4) to adjust our experimental results, we will deduce three characteristic parameters of the crystals : the effective electrooptic coefficient, the saturation intensity and the effective trap density. These parameters will enable to compare the different crystals together.

\subsection{Experimental results}

\section{4.a. Gain as a function of intensity}

The intensity dependence of the gain gives information about the intensity necessary to saturate the gain. It is a very important parameter for some applications like phase conjugation that have a photorefractive gain threshold and where a decrease of the gain can prevent from passing this threshold. The intensity dependence of the gain will allow to determine the power of the laser source that will be necessary to implement such a device. This problem has especially to be considered in the infrared because the photoconductivity of materials like BCT decreases.

We fixed the grating spacing at $1.5 \mu \mathrm{m}^{-1}$, what implies that we have $\mathrm{k}_{\mathrm{r}}^{2}<<\mathrm{k}_{0}^{2}$, leading to a dependence given by :

$\Gamma(\mathrm{I})=\eta(\mathrm{I}) \Gamma_{\infty}=\frac{\Gamma_{\infty}}{1+\frac{\mathrm{I}_{\mathrm{sat}}}{\mathrm{I}}}$

where $\Gamma_{\infty}=\frac{2 \pi}{\lambda_{0}} n^{3} r^{\text {eff }} \frac{k_{B} T}{e} k_{r}$ is the saturated gain. Experimentally, $I_{s a t}$ is the intensity necessary to reach half of the maximum gain.

By fitting the experimental results according to Eq. 5 (Fig.4a), we deduce the values of the saturation intensity for each crystal (Table 1). In Fig.4a, the saturated gain $\Gamma_{\infty}$ is normalized to 1 in order to enable the comparison of the curves. First, we noticed that the saturation intensity decreases when the quantity of rhodium in the crystals goes from 0 to $2000 \mathrm{ppm}$. Furthermore, the saturation intensity of the iron doped crystal is the highest. Second, we noticed that the saturation intensity for the BCT:Rh crystals is between 100 and 1000 time higher than for $\mathrm{BaTiO}_{3}: \mathrm{Rh}$. Indeed, we measured the saturation intensity for a $\mathrm{BaTiO}_{3}: \mathrm{Rh}$ crystal with $2000 \mathrm{ppm}$ of rhodium (labelled Y32-B) and we found 0.5 
$\mathrm{mW} . \mathrm{cm}^{-2}$. It means that we need 100 to 1000 times more intensity to saturate the gain of a BCT:Rh crystal than of a $\mathrm{BaTiO}_{3}: \mathrm{Rh}$ crystal if the crystals are doped with the same amount of rhodium.

\section{4.b. Gain as a function of the grating wave vector}

Measurements of the gain as a function of the grating wave vector are carried out to determine the effective electrooptic coefficient and the effective trap density of the crystals. The measurements are performed with an intensity sufficient to saturate the gain, determined according to the previous measurements. Then, according to Eq. 2, the photorefractive gain expresses as :

$$
\Gamma=\Gamma_{\infty}=\frac{2 \pi}{\lambda_{0}} \mathrm{n}^{3} \frac{\mathrm{k}_{\mathrm{B}} \mathrm{T}}{\mathrm{e}} \mathrm{r}^{\text {eff }} \frac{\mathrm{k}_{\mathrm{r}}}{1+\frac{\mathrm{k}_{\mathrm{r}}^{2}}{\mathrm{k}_{0}^{2}}}
$$

Two kinds of measurements were performed. First, using the arrangement shown in Fig. 3, we measured the two beam coupling gain with copropagating waves. In this configuration, for $\beta=0$, we performed measurements at small grating wave vector $\left(\mathrm{k}_{\mathrm{r}}^{2}<<\mathrm{k}_{0}^{2}\right)$. According to Eq.6, we have :

$\Gamma \approx \frac{2 \pi}{\lambda_{0}} \mathrm{n}^{3} \mathrm{r}^{\mathrm{eff}} \frac{\mathrm{k}_{\mathrm{B}} \mathrm{T}}{\mathrm{e}} \mathrm{k}_{\mathrm{r}}$

The linear dependence of the gain with the grating wave vector enables to determine the effective electrooptic coefficient but will not give a precise value of the effective trap density, which appears as a departure from the linear curve at high value of $\mathrm{k}_{\mathrm{r}}$.

To determine the effective trap density, we carried out another measurement in the configuration presented on Fig. 5, i.e. with counterpropagating beams [7]. In this particular case, with a large grating wave vector $\left(\mathrm{k}_{\mathrm{r}}^{2}>>\mathrm{k}_{0}^{2}\right)$, the gain is dominated by $\mathrm{k}_{0}^{2}$ (i.e. the trap limited field $\mathrm{E}_{\mathrm{q}}$ defined in a one trap model [10]) and this measurement enables to evaluate the effective trap density according to Eq. 4.

No experimental points are given between 7 and $30 \mu \mathrm{m}^{-1}$ because these values of grating wave vector are either forbidden due to refraction laws $\left(14-30 \mu \mathrm{m}^{-1}\right)$ with the crystal cut we used, or correspond to large angle between the beams, what leads to problem for the beams to overlap in the whole crystal (7$\left.14 \mu \mathrm{m}^{-1}\right)$. Nevertheless, the conjugation of copropagative $\left(\mathrm{k}<10 \mu \mathrm{m}^{-1}\right)$ and counterpropagating $\left(\mathrm{k} \approx 30 \mu \mathrm{m}^{-}\right.$ 1) measurements is sufficient to determine precisely the effective trap density [7].

We performed then a simultaneous fit with two parameters on the measurements with copropagating and counterpropagating waves (Fig.4b) using a function of type $\Gamma=\mathrm{Ar}^{\text {eff }} \frac{\mathrm{k}_{\mathrm{r}}}{1+\frac{\mathrm{k}_{\mathrm{r}}^{2}}{\mathrm{k}_{0}^{2}}}$ (A is a known constant). We obtained the effective electrooptic coefficient $\mathrm{r}^{\text {eff }}$ and the parameter $\mathrm{k}_{0}^{2}$ from which we deduced the effective trap density (Eq. 4) using the value of $\varepsilon^{\text {eff }}(0)$ calculated in [4] $\left(\varepsilon^{\text {eff }}(0)=181\right)$. In the configuration of the experiment, the effective electrooptic coefficient is $r_{22}^{\text {eff }}(0)$ and expresses as : 
$r_{22}^{\text {eff }}(0)=r_{13}^{s}+\frac{p_{13}^{\mathrm{E}} e_{33}}{c_{33}^{E}}$

if we consider the indirect electrooptic contributions (elastooptic, elastic and piezoelectric) [4].

In a simpler way, the effective trap density is deduced from the maximum of the curves presented in Fig. $4 \mathrm{~b}$ and the effective electrooptic coefficient is given by the slope of the curves at small grating wave vectors. From the fit, we obtained an almost constant value $\mathrm{N}_{\text {eff }}=(6 \pm 2) \cdot 10^{22} \mathrm{~m}^{-3}$ whatever the crystals (Table 1), whether they were rhodium doped from 200 to $2000 \mathrm{ppm}$, iron doped or undoped. The mean value of the electrooptic coefficient is $r_{22}^{\text {eff }}=(13.5 \pm 1.3) \mathrm{pm} . \mathrm{V}^{-1}$ (Table 1).

\section{4.c. Dependence of the effective trap density on intensity}

We also measured the dependence of the effective trap density on intensity on a $1000 \mathrm{ppm}$ rhodium doped crystal. The experimental conditions are similar as for the previous measurements presented in 1.4.b. This time, we carried out measurements of the gain as a function of the grating wave vector for several intensities. These intensities have been chosen in a range so that the gain depends on intensity. We chose intensities of $2 \mathrm{~W} . \mathrm{cm}^{-2}, 200 \mathrm{~mW} . \mathrm{cm}^{-2}$ and $50 \mathrm{~mW} . \mathrm{cm}^{-2}$. We see in figure 6 that the position of the maximum of the curves, which corresponds to the effective trap density, depends on intensity in the chosen range. Adjustements performed as explained in 1.4.b enable us to determine the effective trap density for each laser intensity. The results presented in table 2 show a dependence of the effective trap density on intensity.

\section{4.d. Determination of $r_{42}^{T}$}

The experimental configuration for the determination of the unclamped value of the electrooptic coefficient $r_{42}^{T}$ is presented in Fig.3 with a crystal oriented such as the grating wave vector is perpendicular to the c-axis. The beams are extraordinary polarized. We performed measurements of the

gain as a function of $\beta$ around $\beta=\frac{\pi}{2}$ with $\mathrm{k}_{\mathrm{r}}=0.8 \mu \mathrm{m}^{-1}$ and we deduced the value of $\mathrm{r}_{42}^{\mathrm{T}}$ from the slope of the experimental curve according to a procedure presented in [4]. These experiments were carried out on two crystals : BCT:Rh 1000 ppm and BCT:Rh 2000 ppm. The results are presented in Fig. 7. We found a value of $276 \mathrm{pm} / \mathrm{V}$ for the $1000 \mathrm{ppm}$ rhodium doped crystal and $215 \mathrm{pm} / \mathrm{V}$ for the $2000 \mathrm{ppm}$ rhodium doped one. Taking into account the accuracy of the measurement, these values are in good accordance with the value of $250 \mathrm{pm} . \mathrm{V}^{-1}$ measured on BCT:Rh $100 \mathrm{ppm}$ at $532 \mathrm{~nm}$ [4].

\subsection{Discussion}

The aim of these experiments was to determine whether rhodium improves the photorefractive properties of BCT crystals at $850 \mathrm{~nm}$. First, we noticed that the absorption spectra show an absorption band proportional to the quantity of rhodium introduced in the melt and that the shape of the curve is similar to the one of $\mathrm{BaTiO}_{3}: \mathrm{Rh}$. Concerning the saturation intensity, the influence of rhodium is positive. Indeed, the saturation intensity decreases from $360 \mathrm{~mW} / \mathrm{cm}^{2}$ for the undoped crystal to 90 $\mathrm{mW} / \mathrm{cm}^{2}$ for the $2000 \mathrm{ppm}$ rhodium doped sample. Nevertheless $90 \mathrm{~mW} / \mathrm{cm}^{2}$ is still a high value 
compared to the saturation intensity obtained in $\mathrm{BaTiO}_{3}: \mathrm{Rh}$ meaning that $\mathrm{BCT}: \mathrm{Rh}$ will require higher power sources to be operated. The results concerning the effective trap density are surprising. First, the effective trap density of the undoped crystal is very high. Second, the effective trap density is the same for all BCT crystals with rhodium doping from 200 to 2000 ppm, with iron doping and without doping. The first point might indicate that a photorefractive impurity is present in large amount in the undoped crystal and is responsible for the large effective trap density. The second point might indicate that the quantity of this impurity is so large that it offsets the influence of rhodium on the effective trap density. It was also noted that the effective trap density of the undoped crystal was very large at $515 \mathrm{~nm}$ [11]. Furthermore, we pointed out that the absorption spectrum of the undoped crystal was proportionnal to the one of the iron doped crystal, so that the impurity contained in the BCT crystals might be iron. Nevertheless, this point is not clear and to have a better understanding, we will now try to modelize the charge transport in BCT:Rh at $850 \mathrm{~nm}$.

\section{CHARGE TRANSPORT SITUATION}

Modelization of the charge transport is of prime importance as it enables the tailoring of the material properties, and will allow the future growth of optimized samples that will meet the requirement of the different applications.

\subsection{The two-level model with three-charge states of rhodium is not valid}

Different characteristic features of $\mathrm{BaTiO}_{3}: \mathrm{Rh}$ can be found in $\mathrm{BCT}: \mathrm{Rh}$. For example, the absorption spectra for $\mathrm{BCT}: \mathrm{Rh}$ and $\mathrm{BaTiO}_{3}: \mathrm{Rh}$ are similar, with a large absorption band around $600 \mathrm{~nm}$, which is attributed to rhodium. In the case of rhodium doping in $\mathrm{BaTiO}_{3}$, it has been established that a two-level model with three charge states of rhodium applies [1,2]. Furthermore, the one-level model is dismissed by the dependence of the effective trap density on the intensity. It is thus natural to consider that BCT:Rh follow a two-center model with three charge states of rhodium, like $\mathrm{BaTiO}_{3}: \mathrm{Rh}$.

As $\mathrm{BCT}$ is close to $\mathrm{BaTiO}_{3}$, we use the results obtained on $\mathrm{BaTiO}_{3}: \mathrm{Rh}$ as starting point. A complete study of $\mathrm{BaTiO}_{3}: \mathrm{Rh}$ was performed by N.Huot [2] at $1.06 \mu \mathrm{m}$. He determined the parameters of the model for $\mathrm{BaTiO}_{3}: \mathrm{Rh}$ at this wavelength :

- the total amount of rhodium in a $1000 \mathrm{ppm}$ rhodium doped sample and the different parameters related to $\mathrm{Rh}^{4+}$ and $\mathrm{Rh}^{5+}$ :

- the photoionisation cross sections.

- the recombination rates.

- the thermal emission rates.

Among these parameters, only the photoionisation cross sections depend on the wavelength. To determine their values at $850 \mathrm{~nm}$, we performed measurements on $\mathrm{BaTiO}_{3}: \mathrm{Rh}$ at $850 \mathrm{~nm}$ using the same experimental procedure and the same samples as in [2]. The determined photoionisation cross section of $\mathrm{Rh}^{4+}$ and $\mathrm{Rh}^{5+}$ at $850 \mathrm{~nm}$ rhodium parameters for $\mathrm{BaTiO}_{3}: \mathrm{Rh}$ at $850 \mathrm{~nm}$ are given in table 3 (second column). 
This set of parameters was a basis to begin our simulations on BCT:Rh. We simulated numerically the dependence of the gain on the grating spacing for several amounts of rhodium (200 ppm, 1000 ppm and $2000 \mathrm{ppm}$ ) according to a two-level model with three charge states of rhodium. To estimate the total quantity of rhodium in the crystals, we assumed that it was proportional to the amount of rhodium in the melt. Furthermore, we supposed that the quantity of rhodium that entered a crystal of BCT was the same as for a crystal of $\mathrm{BaTiO}_{3}$. As the rhodium parameters for BCT:Rh might be slightly different from the ones of $\mathrm{BaTiO}_{3}: \mathrm{Rh}$, we then varied each parameter around its initial value. But, whatever the parameters we chose, simulations indicated always a variation of the effective trap density with rhodium doping (Fig. 8a) which is much larger than the one observed experimentally (Fig.8b). Indeed, comparing both figures ( $8 \mathrm{a}$ and $8 \mathrm{~b}$ ), we see that the variation of the effective trap density (which corresponds to the variation of theposition of the maximum of the curves) induced by a variation of the concentration of rhodium is much lower experimentally $\left[13-17 \mu \mathrm{m}^{-1}\right]$ than on the simulated curves $\left[7-15 \mu \mathrm{m}^{-1}\right]$.

Therefore, it seems that a two-level model with three charge states of rhodium cannot explain the photorefractive effect in BCT:Rh. This point is confirmed by the fact that the undoped and iron doped samples are sensitive at $850 \mathrm{~nm}$ and they exhibit the same large effective trap density as the rhodium doped samples. Indeed, it should indicate that an impurity is present in these crystals in large amount and is responsible for the photorefractive effect at this wavelength. As the effective trap density in the rhodium doped samples is independent of the quantity of rhodium and is the same as in the undoped and iron doped crystals, it seems possible that the same impurity is responsible for the photorefractive effect in all crystals. Several points tend to indicate that this impurity might be iron. First, the absorption spectra of the undoped and iron doped samples are proportionnal as mentionned in 1.1. Then, EPR measurements made at the University of Osnabrück indicated the presence of a large amount of iron in the rhodium doped crystals [12]. Finally, it is well known that $\mathrm{BaTiO}_{3}: \mathrm{Rh}$ contains iron as major native impurity. But, opposite to $\mathrm{BaTiO}_{3}: \mathrm{Rh}$, where the presence of iron was neglected, it seems here necessary to take it into account to modelize the photorefractive effect in $\mathrm{BCT}: \mathrm{Rh}$. Indeed, the amount of iron in the BCT crystals seems to be much larger than in the $\mathrm{BaTiO}_{3}$ crystals. It might be due to the growth temperature, which is $200^{\circ} \mathrm{C}$ higher for BCT, that favors the incorporation of iron in the crystal. That is why we think that the photorefractive model that best explains the photorefractive properties of $\mathrm{BCT}: \mathrm{Rh}$ is a three-level model with two-level of rhodium and one level of iron.

\subsection{Charge transport model in BCT:Rh}

Here we briefly present the three-level model and the simulations, which have given a good accordance between the model and the experimental results.

\section{2.a. Description of the three-level model :}

We consider a three level model with two levels of rhodium $\left(\mathrm{Rh}^{3+/ 4+}, \mathrm{Rh}^{4+/ 5+}\right)$ and one level of iron $\left(\mathrm{Fe}^{3+/ 4+}\right)$. When the crystal is illuminated, we have the following charge transfers : 
$\left\{\begin{aligned} \mathrm{Rh}^{5+} & \leftrightarrow \mathrm{Rh}^{4+}+\text { hole } \\ \mathrm{Rh}^{4+} & \leftrightarrow \mathrm{Rh}^{3+}+\text { hole } \\ \mathrm{Fe}^{4+} & \leftrightarrow \mathrm{Fe}^{3+}+\text { hole }\end{aligned}\right.$

We consider $\mathrm{Rh}^{4+}$ and $\mathrm{Fe}^{4+}$ as neutral states of charges and we note them respectively $\mathrm{N}$ and $\mathrm{N}_{\mathrm{F}}$. Then $\mathrm{Rh}^{3+}$ and $\mathrm{Fe}^{3+}$ can be considered as recombination centers and $\mathrm{Rh}^{5+}$ as a generation center for holes. Their densities are respectively $\mathrm{N}^{-}, \mathrm{N}_{\mathrm{F}}^{-}$and $\mathrm{N}^{+}$. The electrical neutrality of the crystal is achieved by shallow donor and acceptor densities $N_{D}$ and $N_{A}$. The compensation density is noted $N_{d a}=N_{D}-N_{A} \cdot p$ is the density of free holes in the valence band.

A schematic diagram of the structure of the dopant levels is shown in Fig.9.

The photoionization cross-sections are noted $S, \beta$ are the thermal emission rates and $\gamma$ the rates of recombination.

If $\mathrm{N}_{\mathrm{T}}$ is the total density of rhodium and $\mathrm{N}_{\mathrm{TF}}$ the total density of iron, we have :

$\left\{\begin{array}{c}\mathrm{N}_{\mathrm{T}}=\mathrm{N}^{-}+\mathrm{N}+\mathrm{N}^{+} \\ \mathrm{N}_{\mathrm{TF}}=\mathrm{N}_{\mathrm{F}}^{-}+\mathrm{N}_{\mathrm{F}}\end{array}\right.$

The rate equations are :

$\left\{\begin{array}{l}\frac{\partial \mathrm{N}^{-}}{\partial \mathrm{t}}=\left(\mathrm{S}^{-} \mathrm{I}+\beta^{-}\right) \mathrm{N}-\gamma^{-} \mathrm{pN}^{-} \\ \frac{\partial \mathrm{N}^{+}}{\partial \mathrm{t}}=-\left(\mathrm{S}^{+} \mathrm{I}+\beta^{+}\right) \mathrm{N}^{+}+\gamma^{+} \mathrm{pN} \\ \frac{\partial \mathrm{N}_{\mathrm{F}}^{-}}{\partial \mathrm{t}}=\left(\mathrm{S}_{\mathrm{F}} \mathrm{I}+\beta_{\mathrm{F}}\right) \mathrm{N}_{\mathrm{F}}-\gamma_{\mathrm{F}} \mathrm{pN}_{\mathrm{F}}^{-}\end{array}\right.$

The current density and the continuity equation for holes are :

$\operatorname{div} \vec{j}=e \frac{\partial\left(N_{D A}+p+N^{+}-N^{-}-N_{F}^{-}\right)}{\partial t}$

$\vec{j}=e p \mu \vec{E}-\mu k_{B} T \overrightarrow{\nabla p}$

Poisson' s equation relates the electric field $\vec{E}$ to the charge densities :

$\operatorname{div} \vec{E}=\frac{e}{\varepsilon}\left(N_{D A}+p+N^{+}-N^{-}-N_{F}^{-}\right)$

Then, we perform a classical resolution of these equations under an interference pattern illumination $\mathrm{I}=\mathrm{I}_{0}+\frac{1}{2}\left(\mathrm{~m} \cdot \mathrm{I}_{0} \mathrm{e}^{\mathrm{ikx}}+\mathrm{c} . \mathrm{c}\right.$.) (with $\mathrm{I}_{0}$ the total incident illumination and $\mathrm{m}$ the modulation of the fringes). 
We write each quantity as $\mathrm{Q}=\mathrm{Q}_{0}+\frac{1}{2}\left(\mathrm{Q}_{1} \mathrm{e}^{\mathrm{ikx}}+\right.$ c.c. $)$, and linearize the equations, to obtain two sets of equations. The "zeroth-order" set relates the space-invariant quantities $\mathrm{Q}_{0}$ to $\mathrm{I}_{0}$. The "first-order" set defines the amplitude of the induced space-charge field as a function of the modulation of the fringes. The sets are then solved numerically and we calculate the photorefractive gain as a function of the grating spacing and the pump intensity to compare with the experimental results.

\section{2.b. Determination of the initial parameters}

Following parameters are necessary for the simulations :

- rhodium parameters : the photoionisation cross-sections $S^{+}$and $S^{-}$, the thermal ionization rates $\beta_{+}$and $\beta_{\text {- }}$, the recombination rates $\gamma^{+}$and $\gamma^{-}$and the total density of rhodium $\mathrm{N}_{\mathrm{T}}$.

- iron parameters : the photoionisation cross-section $S_{F}$, the thermal ionization rate $\beta_{F}$, the recombination rate $\gamma_{\mathrm{F}}$ and the total density of iron $\mathrm{N}_{\mathrm{TF}}$.

- the compensation density $\mathrm{N}_{\mathrm{da}}$.

For all the following numerical simulations, we supposed that the Fermi-level did not change with rhodium doping. So $\mathrm{N}_{\mathrm{da}}$ was considered as a constant in all the crystals.

For the rhodium parameters, we used as initial values the $\mathrm{BaTiO}_{3}: \mathrm{Rh}$ ones determined at $850 \mathrm{~nm}$ (Table 3 , second column).

To determine the iron parameters, we used the experimental results on the undoped crystal. Indeed, we considered that the photorefractive effect in this crystal was only due to iron. We simulated a charge transport model with one center $\left(\mathrm{Fe}^{3+/ 4+}\right)$. The initial values of the parameters were chosen according to [13], which gives indications about parameters for the iron level in $\mathrm{BaTiO}_{3}: \mathrm{Rh}: \beta_{\mathrm{F}}$ might be of the order of $5.10^{-4} \mathrm{~s}^{-1}, S_{F}$ might be small compared to $S^{-}$and $\gamma_{F}$ is not given and will be taken equal to $\gamma^{+}$in $\mathrm{BaTiO}_{3}: \mathrm{Rh}$ (Table 3, second column). By adjusting the simulated curves to the experimental results, we obtained several informations about the values of the parameters. First, the dependence of the gain with intensity allowed us to precise both parameters $S_{F}$ and $\beta_{F}$. Second, the value of the effective trap density gave us a minimum value for the quantity of iron contained in the crystal. Indeed, in the case of a onecenter model, we have :

$\mathrm{N}_{\text {eff }}=\mathrm{N}_{\mathrm{F}}^{-}-\frac{\mathrm{N}_{\mathrm{da}}^{2}}{\mathrm{~N}_{\mathrm{TF}}}=\mathrm{N}_{\mathrm{da}} \frac{\left(\mathrm{N}_{\mathrm{TF}}-\mathrm{N}_{\mathrm{da}}\right)}{\mathrm{N}_{\mathrm{TF}}}$

which can be written :

$\mathrm{N}_{\mathrm{da}}^{2}-\mathrm{N}_{\mathrm{TF}} \mathrm{N}_{\mathrm{da}}+\mathrm{N}_{\mathrm{eff}} \mathrm{N}_{\mathrm{TF}}=0$

To have a solution of this second order equation, we should have :

$\mathrm{N}_{\mathrm{TF}}\left(\mathrm{N}_{\mathrm{TF}}-4 \mathrm{~N}_{\text {eff }}\right) \geq 0$ which corresponds to $\mathrm{N}_{\mathrm{TF}} \geq 4 \mathrm{~N}_{\text {eff }}$

And, knowing the value of the effective trap density $\left(6.10^{22} \mathrm{~m}^{-3}\right)$, we have $\mathrm{N}_{\mathrm{TF}} \geq 24.10^{22} \mathrm{~m}^{-3}$. 
When the value of $\mathrm{N}_{\mathrm{TF}}$ is fixed, we obtained two values for the compensation density $\mathrm{N}_{\mathrm{da}}$ : one is of the same order of magnitude as $\mathrm{N}_{\mathrm{TF}}$ and the other is small compared to $\mathrm{N}_{\mathrm{TF}}$. Simulations showed that it is better to choose the smallest one according to experimental results.

\section{2.c. Numerical simulations}

With this initial set of parameters, we performed numerical simulations simultaneously on the undoped and rhodium doped samples for several amount of rhodium (200, 370, 600, 1000 and 2000 $\mathrm{ppm})$. Our aim is to find a set of parameters which enables to explain our experimental results. To do this, we vary the parameters around their initial values to improve the accordance between simulated curves and experimental ones. It was possible to find a convenient set of parameters (Table 3, first column) so that the simulated curves were in good accordance with the experimental results (Fig.10). Figure 10a represents the dependence of the gain on intensity. The experimental points and the simulated curves are represented. We consider that we obtained a good accordance because a slight variation of some parameters induces a large translation of the curves. In figure $10 \mathrm{~b}$, we have represented the dependence of the gain with the grating spacing. The lines corresponds to simulations and we see that they are in good accordance with the experimental points

\subsection{Validity of the model}

Considering the number of unknown parameters, this set is certainly not the only one existing but the founded values seem to make sense. First, the values obtained for the rhodium parameters in BCT are not far from the ones obtained for $\mathrm{BaTiO}_{3}: \mathrm{Rh}$ at the same wavelength. Second, the large amount of iron that is found in BCT crystals is in good accordance with results obtained at the University of Osnabrïck [12]. Moreover, it enables to explain the independence of the effective trap density on rhodium and iron doping. Indeed, it seems that the quantity of dopant added (rhodium or iron) is negligible compared to the amount of iron already present in the crystals because it does not change the effective trap density. But this point has to be further studied.

\section{COMPARISON OF BCT:Rh WITH BATIO $3:$ Rh}

$\mathrm{BCT}: \mathrm{Rh}$ is a good photorefractive material. Most of its photorefractive properties are not far from the ones of $\mathrm{BaTiO}_{3}: \mathrm{Rh}$.

The electrooptic coefficient $r_{42}^{\mathrm{T}}$ is really smaller than in $\mathrm{BaTiO}_{3}$ but it still has a value that should be sufficient for applications such as phase conjugation. The ordinary photorefractive gain is of the same order of magnitude in both crystal. Indeed, the gain measured in a $2000 \mathrm{ppm} \mathrm{BaTiO} 3: \mathrm{Rh}_{\text {(labelled X15) }}$ at $850 \mathrm{~nm}$ in a symmetrical configuration, with ordinary polarizations and for a grating wave vector of $3.6 \mu \mathrm{m}^{-1}$ is around $1.1 \mathrm{~cm}^{-1}$ whereas it is around $1.3 \mathrm{~cm}^{-1}$ in a $2000 \mathrm{ppm} \mathrm{BCT:Rh} \mathrm{(Fig.4b)}$

The smallest response time is measured for a $2000 \mathrm{ppm}$ rhodium doped BCT with counterpropagating waves and was around $3 \mathrm{~s}$ for an intensity of $1 \mathrm{~W} . \mathrm{cm}^{-2}$. To compare with $\mathrm{BaTiO}_{3}: \mathrm{Rh}$, we measured $8 \mathrm{~s}$

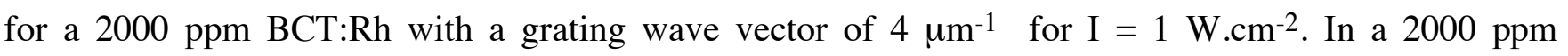
$\mathrm{BaTiO}_{3}: \mathrm{Rh}$ (labelled Y32-B), we measured $\tau=60 \mathrm{~s}$ for $\mathrm{I}=600 \mathrm{~mW} . \mathrm{cm}^{-2}$ for the same grating spacing 
and the same wavelength. As the response time in $\mathrm{BaTiO}_{3}: \mathrm{Rh}$ is proportionnal to $\mathrm{I}^{-1}$, we should have a response time of $36 \mathrm{~s}$ for $\mathrm{I}=1 \mathrm{~W} . \mathrm{cm}^{-2}$. Thus the response time is better in $\mathrm{BCT}: \mathrm{Rh}$ than in $\mathrm{BaTiO}_{3}: \mathrm{Rh}$ for the same amount of rhodium.

The saturation intensity is the unique parameter that differs a lot between both crystals. It is 100 to 1000 times higher in $\mathrm{BCT}: \mathrm{Rh}$ than in $\mathrm{BaTiO}_{3}: \mathrm{Rh}$ due to the influence of iron.

\section{CONCLUSION}

$\mathrm{BCT}: \mathrm{Rh}$ crystals are sensitive in the infrared at $850 \mathrm{~nm}$. Rhodium doping improves this sensitivity in term of saturation intensity but the obtained saturation intensities are still very high compared to the ones of $\mathrm{BaTiO}_{3}: \mathrm{Rh}$. Moreover, rhodium doping up to $2000 \mathrm{ppm}$ does not improve the effective trap density. It might be due to the presence of a large amount of iron in the crystals. Indeed, to explain the experimental results, we need to take into account the presence of iron in our charge transport model. Iron seems to be responsible for the high saturation intensity, what can be a drawback for some applications. To improve this characteristics of the BCT:Rh crystals, the next step in the developpement will be to test crystals doped with a larger amount of rhodium.

ACKNOWLEDGEMENT : Valuable discussions with D.Rytz, O.F.Schirmer and G.Malovichko are gratefully acknowledged.

\section{REFERENCES}

[1] H.Kröse, R.Scharfschwerdt, O.F.Schirmer, H.Hesse, "Light-induced charge transport in $\mathrm{BaTiO}_{3}$ via three charge states of rhodium", Appl. Phys. B 61, 1 (1995).

[2] N.Huot, J.M.C.Jonathan, G.Roosen, "Validity of the three charge state model in photorefractive $\mathrm{BaTiO}_{3}: \mathrm{Rh}$ at $1.06 \mu \mathrm{m}$ in the cw regime", Appl. Phys. B. 65, 486 (1997).

[3] Ch.Kuper, K.Buse, U.Van Stevendaal, M.Weber, T.Leidlo, H.Hesse, E.Krätzig, "Electrooptic and photorefractive properties of ferroelectric barium-calcium titanate crystals", Ferroelectrics 208-209, 213 (1998)

[4] S.Bernhardt, P.Delaye, H.Veenhuis, G.Roosen, "Photorefractive two-beam coupling characterization of a barium-calcium titanate crystal”, Appl. Phys. B 70, 789 (2000).

[5] H.Veenhuis, T.Börger, K.Peithmann, M.Flaspöhler, K.Buse, R.Pankrath, H.Hesse, E.Krätzig, "Light-induced charge transport properties of photorefractive Barium-calcium-titanate crystals doped with rhodium", Appl.Phys. B 70, 797 (2000)

[6] H.Kröse, R.Schrafschwerdt, O.F.Schirmer, H.Hesse, "Light-induced charge transport in $\mathrm{BaTiO}_{3}$ via three charge states of rhodium", Appl. Phys. B, 61, 1-7, (1995). 
[7] Ph.Delaye, L.A. de Montmorillon, I.Biaggio, J.C.Launay, G.Roosen, "Wavelength dependent effective trap density in CdTe : evidence for the presence of two photorefractive species", Optics Commun. 134, 580-590 (1997).

[8] K.Buse, "Light induced charge transport processes in photorefractive crystals I: Models and experimental methods", Appl. Phys. B 64, 273-291 (1997), K.Buse, "Light-induced charge transport processes in photorefractrive crystals II: Materials.", Appl. Phys. B, 64, 391 (1997) .

[9] F.P.Strohkendl, J.M.C.Jonathan and R.W.Hellwarth, "Hole-electron competition in photorefractive gratings", Opt. Lett. 11, 5 (1986).

[10] N.V.Kukhtarev, V.B.Markov, S.G.Odulov, M.S.Soskin and V.L.Kinetskii, "Holographic storage in electrooptic crystals. I. Steady State", "Holographic storage in electrooptic crystals. II. Beam-coupling light amplification", Ferroelectrics 22, 949 (1979).

[11] H.Veenhuis, T.Börger, K.Buse, C.Kuper, H.Hesse, E.Krätzig, "Light-induced charge transport properties of photorefractive Barium-calcium-titanate crystals doped with iron", J. Appl.Phys. 88, 1042 (2000)

[12] O.F.Schirmer, private communication.

[13] L.Corner, R.Ramos-Garcia, A.Petris, M.J.Damzen, "Experimental and theoretical characterization of rhodium doped barium titanate", Opt. Commun. 143, 165 (1997). 


\section{TABLE CAPTIONS}

Table 1 : Values of the saturation intensity, the effective trap density and the effective electrooptic coefficient determined for all studied crystals.

Table 2 : Dependence of the effective trap density and of the saturation coefficient $\eta$ on intensity for a 1000 ppm rhodium doped BCT.

Table 3 : Set of parameters found to fit the experimental results in the case of a three-level model. The parameters of $\mathrm{BaTiO}_{3}: \mathrm{Rh}$ determined at $850 \mathrm{~nm}$ according to a two-level model with three-charge states of rhodium are presented for comparison.

\section{FIGURE CAPTIONS}

Figure 1 : Absorption as a function of wavelength for BCT:Rh crystals doped with different amounts of rhodium.

Figure 2: (a) Absorption spectra of BCT:Rh from which we have substracted the absorption of the undoped sample and that we have divided by the amount of rhodium in the melt. (b) Absorption spectra for BCT:Fe and undoped BCT. The absorption spectra of the undoped crystal multiplied by 1.65 is almost identical to the absorption spectra of BCT:Fe.

Figure 3 : Experimental set-up for two-beam coupling experiments with copropagating waves; $\mathrm{M}$ : mirror, BS : beam splitter 50/50, $\mathrm{H}$ : hole, $\mathrm{P}$ : polarizor, $\mathrm{D}$ : detector.

Figure 4 : (a) Normalized photorefractive gain as a function of intensity. (b) Photorefractive gain in ordinary polarization as a function of the grating wave vector. In both figures, the points correspond to experiments and the lines corresponds to the fitting curves. ${ }^{-}$undoped BCT, $\mathbf{B C T}: \mathrm{Rh} 200 \mathrm{ppm}$, 米

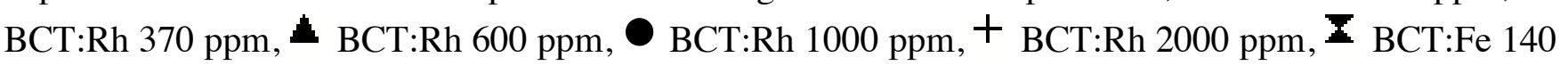
ppm.

Figure 5 : Experimental set-up for the measurement of the gain with counterpropagating waves.

Figure 6 : Dependence of the gain with the grating wave vector for several laser intensities for a 1000 ppm rhodium doped BCT crystal. 
Figure 7 : Experimental photorefractive gain $\Gamma$ as a function of the angle between the grating wave vector and the $c$-axis around $(\beta=\pi / 2)$.

Figure 8 : (a) Effect of the variation of the amount of rhodium on the effective trap density in BCT:Rh, calculated according to a two-level model with three-charge states of rhodium. (b) Experimental dependence of the effective trap density on the amount of rhodium in BCT:Rh. The experimental points are represented as well as the fitting curves (the fit procedure is explained in 1.4.b). In both figures, the vertical lines show the maximum of the curves from which we deduce the effective trap density.

Figure 9 : Schematic energy level diagram of BCT:Rh containing iron as an impurity.

Figure 10 : Comparison between experimental points and simulated curves with simulations according to a three-level model with two levels of rhodium and one level of iron. Concerning the simulated curves of the gain as a function of the grating wave vector, we use in the calculations the value of $r_{22}^{\text {eff }}$ experimentally determined for each crystal (see table 1). Figure 10 a represents the dependance of the normalized gain with intensity and figure $10 \mathrm{~b}$ concerns the dependence of the gain with the grating spacing. $\otimes$ undoped BCT, B BCT:Rh 200 ppm, ${ }^{*}$ BCT:Rh 370 ppm, $\boldsymbol{A}$ BCT:Rh 600 ppm, BCT:Rh 1000 ppm, ${ }^{+}$BCT:Rh 2000 ppm. 


\begin{tabular}{|c|c|c|c|}
\hline Crystal & $\mathrm{I}_{\text {sat }}\left(\mathrm{mW} / \mathrm{cm}^{2}\right)$ & $\mathrm{N}_{\mathrm{eff}}\left(\mathrm{m}^{-3}\right)$ & $\mathrm{r}_{22}^{\text {eff }}(\mathrm{pm} / \mathrm{V})$ \\
\hline BCT:Fe $140 \mathrm{ppm}$ & 1300 & $5.4 .10^{22}$ & 15 \\
\hline undoped BCT & 360 & $6.2 .10^{22}$ & 11.6 \\
\hline BCT:Rh $200 \mathrm{ppm}$ & 190 & $4.9 .10^{22}$ & 12.8 \\
\hline BCT:Rh $370 \mathrm{ppm}$ & 170 & $6.1 .10^{22}$ & 13 \\
\hline BCT:Rh $600 \mathrm{ppm}$ & 110 & $7.1 .10^{22}$ & 12.8 \\
\hline BCT:Rh $1000 \mathrm{ppm}$ & 100 & $5.3 .10^{22}$ & 13.6 \\
\hline ВCT: $:$ h $2000 \mathrm{ppm}$ & 90 & $7.2 .10^{22}$ & 15.3 \\
\hline
\end{tabular}

Table 1 


\begin{tabular}{|c|c|c|}
\hline Intensity $\left(\mathbf{W} / \mathbf{c m}^{2}\right)$ & Effective trap density $\left(\mathbf{m}^{\mathbf{3}}\right)$ & $\boldsymbol{\eta}(\mathbf{I})$ \\
\hline 2 & $6.5 .10^{22}$ & 1 \\
\hline 0.2 & $5.9 .10^{22}$ & 0.75 \\
\hline 0.05 & $4.1 .10^{22}$ & 0.54 \\
\hline
\end{tabular}

Table 2 


\begin{tabular}{|c|c|c|}
\hline Parameters & $\begin{array}{c}\text { Adjusted value } \\
\text { for BCT:Rh }\end{array}$ & $\begin{array}{c}\text { Adjusted value } \\
\text { for BaTiO } \mathbf{~} \text { :Rh }\end{array}$ \\
\hline Photoionization cross section of $\mathrm{Rh}^{5+}: \mathrm{S}^{+}\left(\mathrm{m}^{2}\right)$ & $9 \mathrm{e}-21$ & $1,24 \mathrm{e}-21$ \\
\hline Photoionization cross section of $\mathrm{Rh}^{4+}: \mathrm{S}^{-}\left(\mathrm{m}^{2}\right)$ & $0.4 \mathrm{e}-21$ & $0,56 \mathrm{e}-21$ \\
\hline Photoionization cross section of $\mathrm{Fe}^{4+}: \mathrm{S}_{\mathrm{F}}\left(\mathrm{m}^{2}\right)$ & $0.001 \mathrm{e}-21$ & - \\
\hline Recombination rate of $\mathrm{Rh}^{5+}\left(\mathrm{m}^{3} / \mathrm{s}\right): \gamma_{+}$ & $2.92 \mathrm{e}-14$ & $3,5 \mathrm{e}-14$ \\
\hline Recombination rate of $\mathrm{Rh}^{4+}\left(\mathrm{m}^{3} / \mathrm{s}\right): \gamma_{-}$ & $15^{*} \gamma_{+}$ & $1.5^{*} \gamma_{+}$ \\
\hline Recombination rate of $\mathrm{Fe}^{4+}\left(\mathrm{m}^{3} / \mathrm{s}\right): \gamma_{\mathrm{F}}$ & $\gamma_{+}$ & - \\
\hline Thermal emission rate of $\mathrm{Rh}^{5+}\left(\mathrm{s}^{-1}\right): \beta^{+}$ & 2.3 & 2.3 \\
\hline Thermal emission rate of $\mathrm{Rh}^{4+}\left(\mathrm{s}^{-1}\right): \beta^{-}$ & 0.0001 & 0,01 \\
\hline Thermal emission rate of $\mathrm{Fe}^{4+}\left(\mathrm{s}^{-1}\right): \beta_{\mathrm{F}}$ & 0.000125 & - \\
\hline Total Iron concentration $\left(\mathrm{m}^{-3}\right): \mathrm{N}_{\mathrm{F}}$ & $64 \mathrm{e} 23$ & - \\
\hline Compensation density $\left(\mathrm{m}^{-3}\right): \mathrm{N}_{\mathrm{DA}}$ & $0.82 \mathrm{e} 23$ & $3.3 \mathrm{e} 23$ \\
\hline Total Concentration of rhodium for a $1000 \mathrm{ppm}$ & $3.3 \mathrm{e} 23$ & \\
\hline doped sample $\left(\mathrm{m}^{-3}\right): \mathrm{N}_{\mathrm{T}}$ & & \\
\hline
\end{tabular}

\section{Table 3}




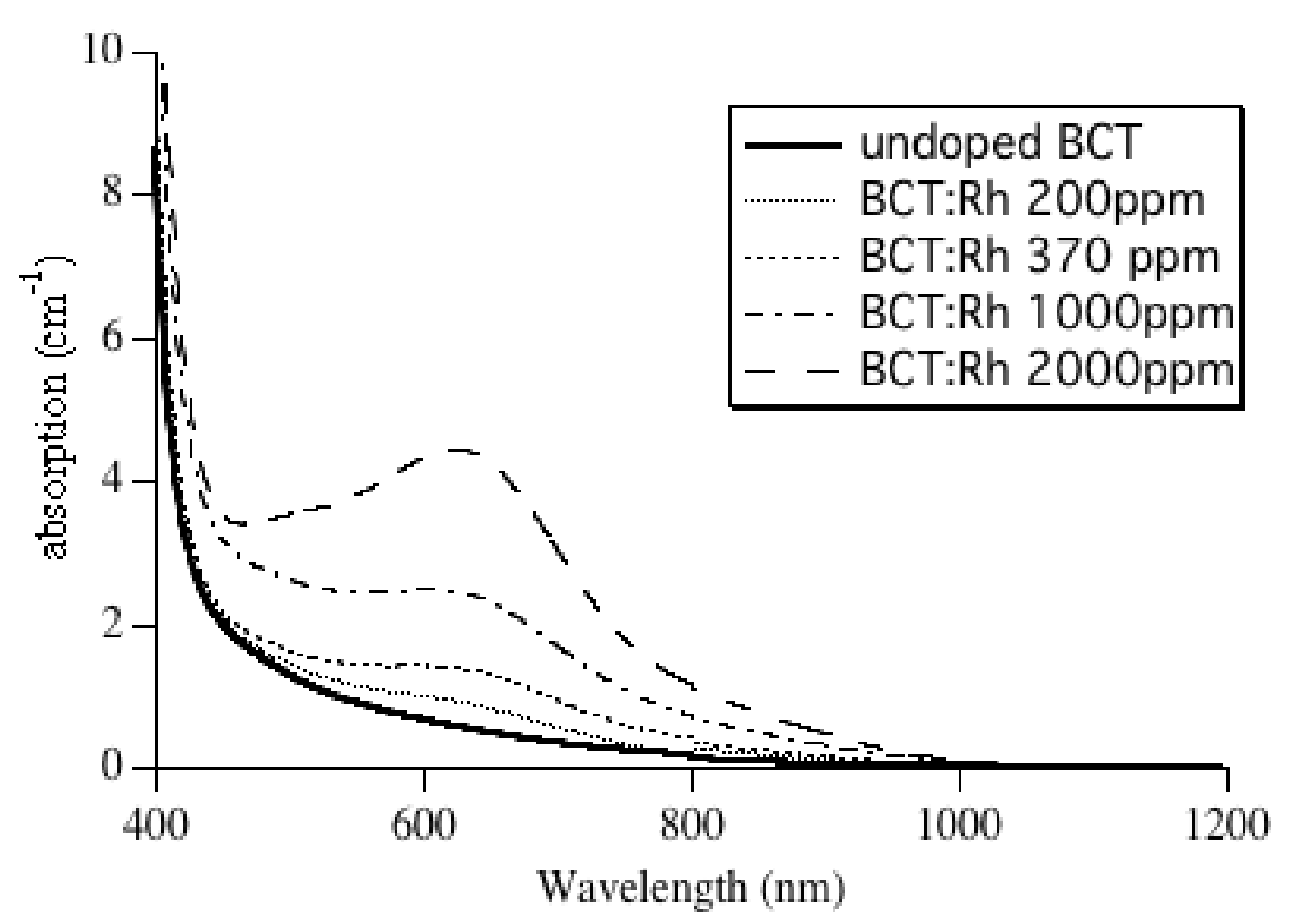

Figure 1 

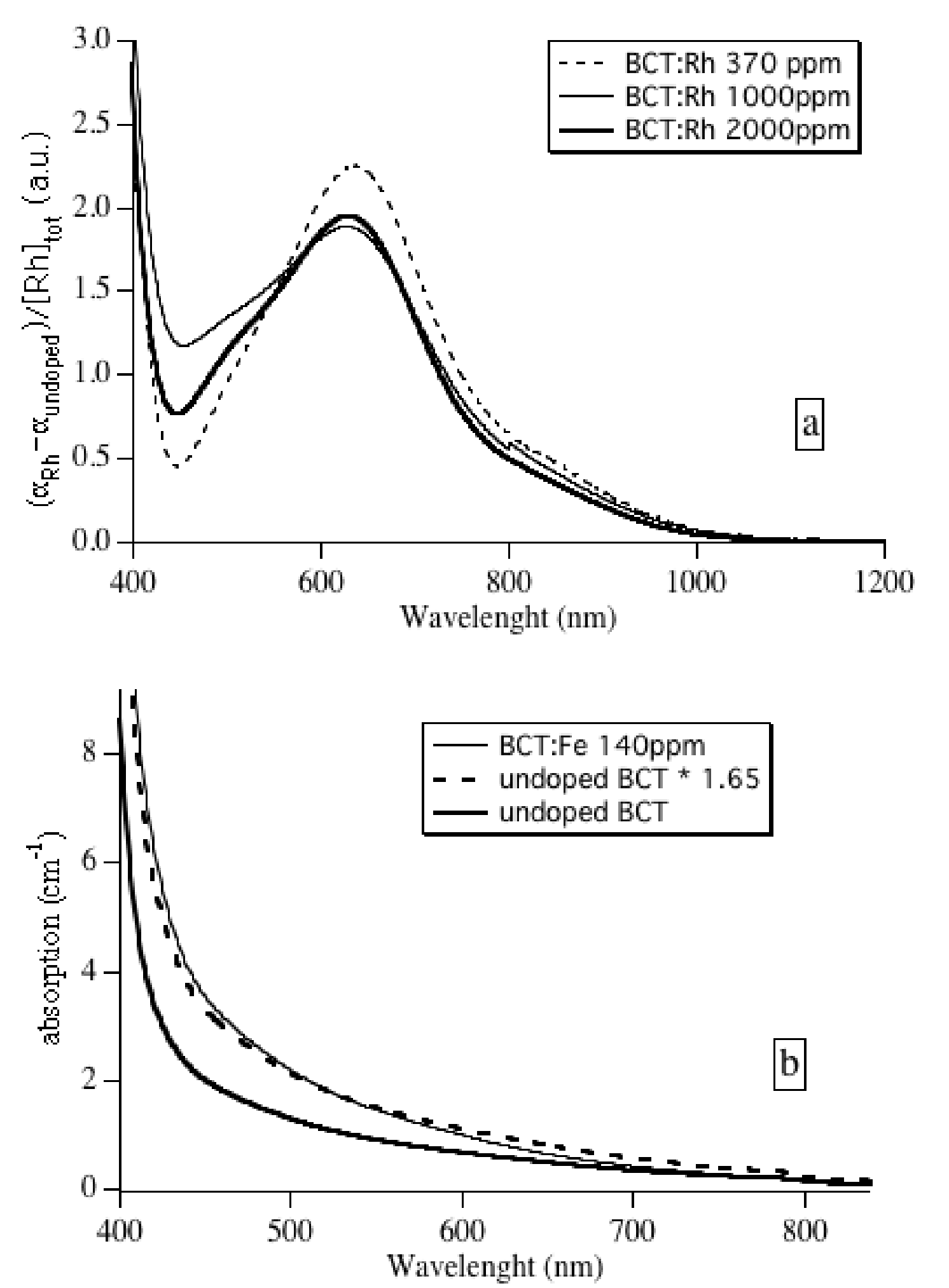

Figure 2 


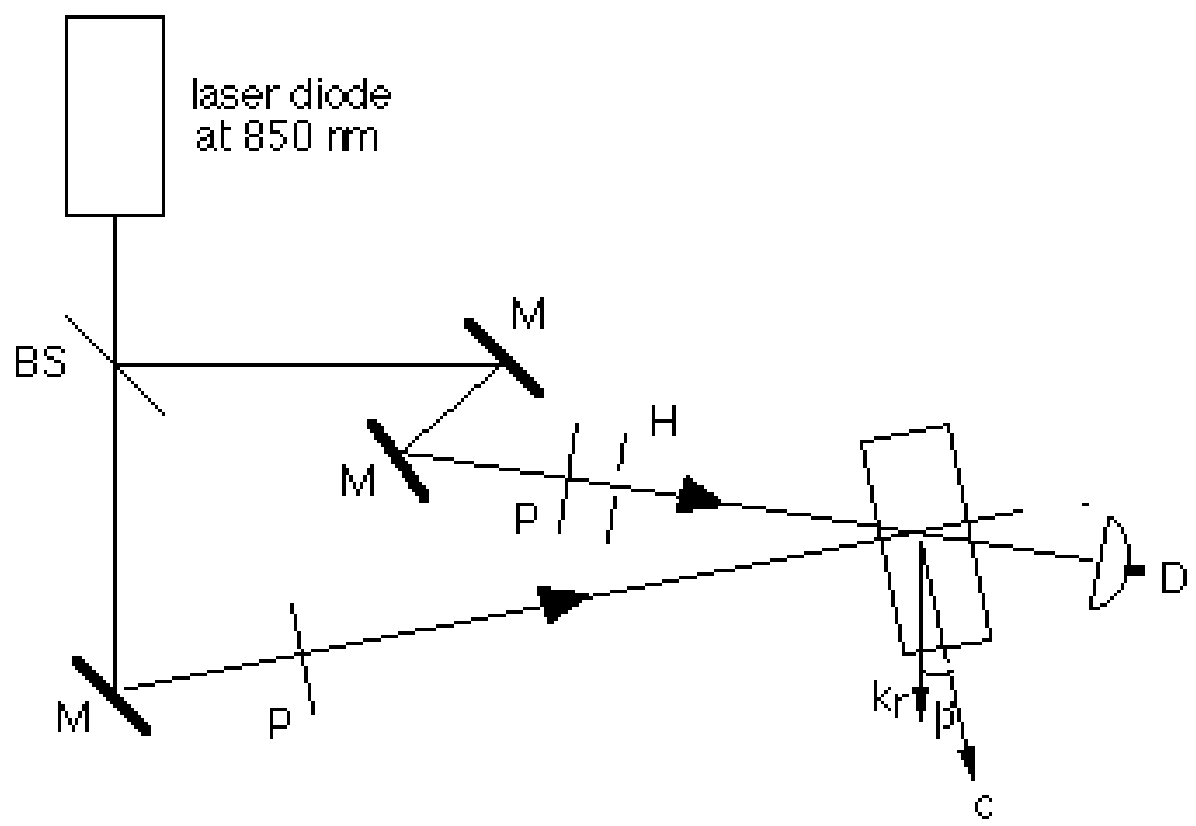

Figure 3 

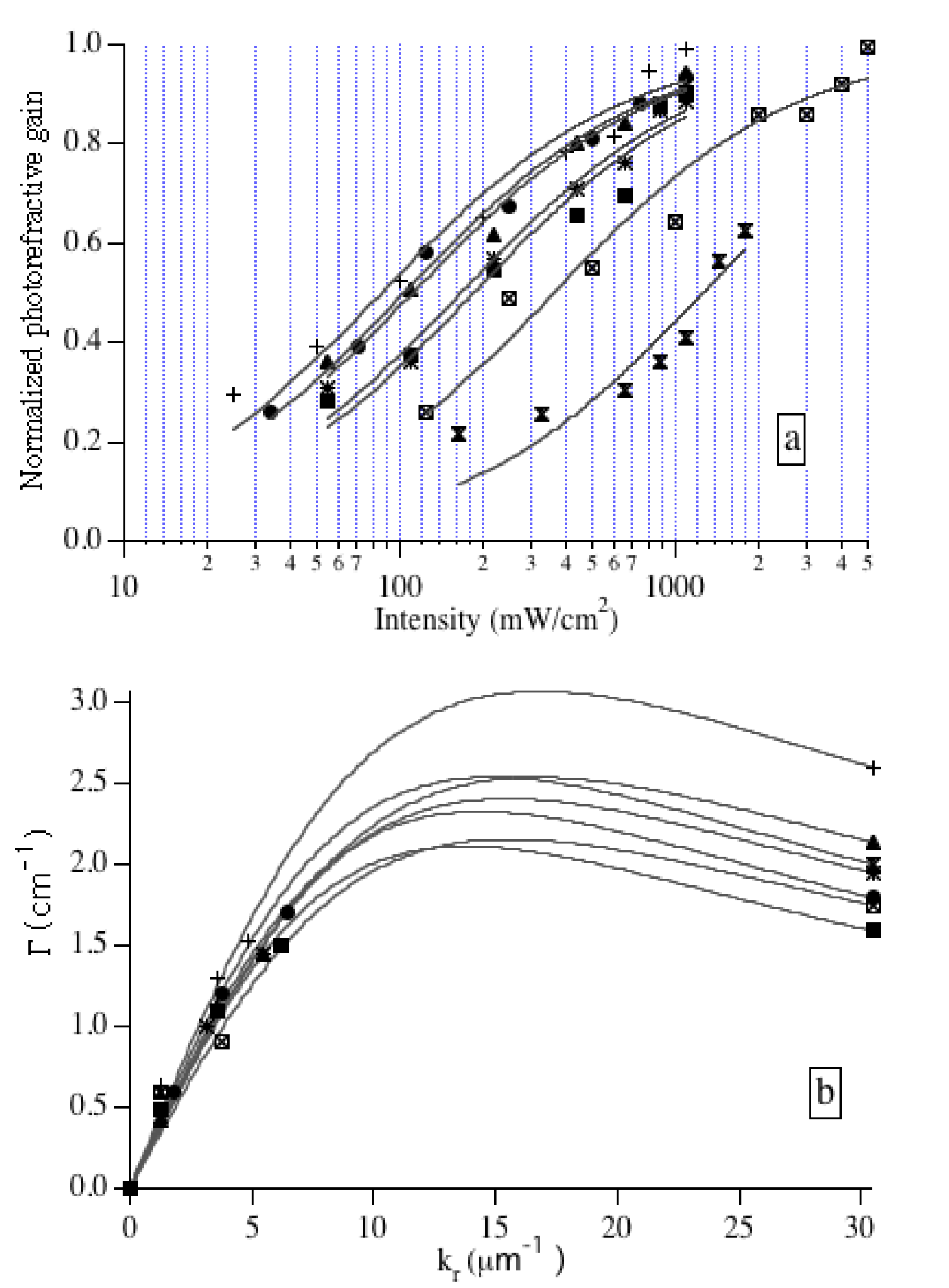

Figure 4 


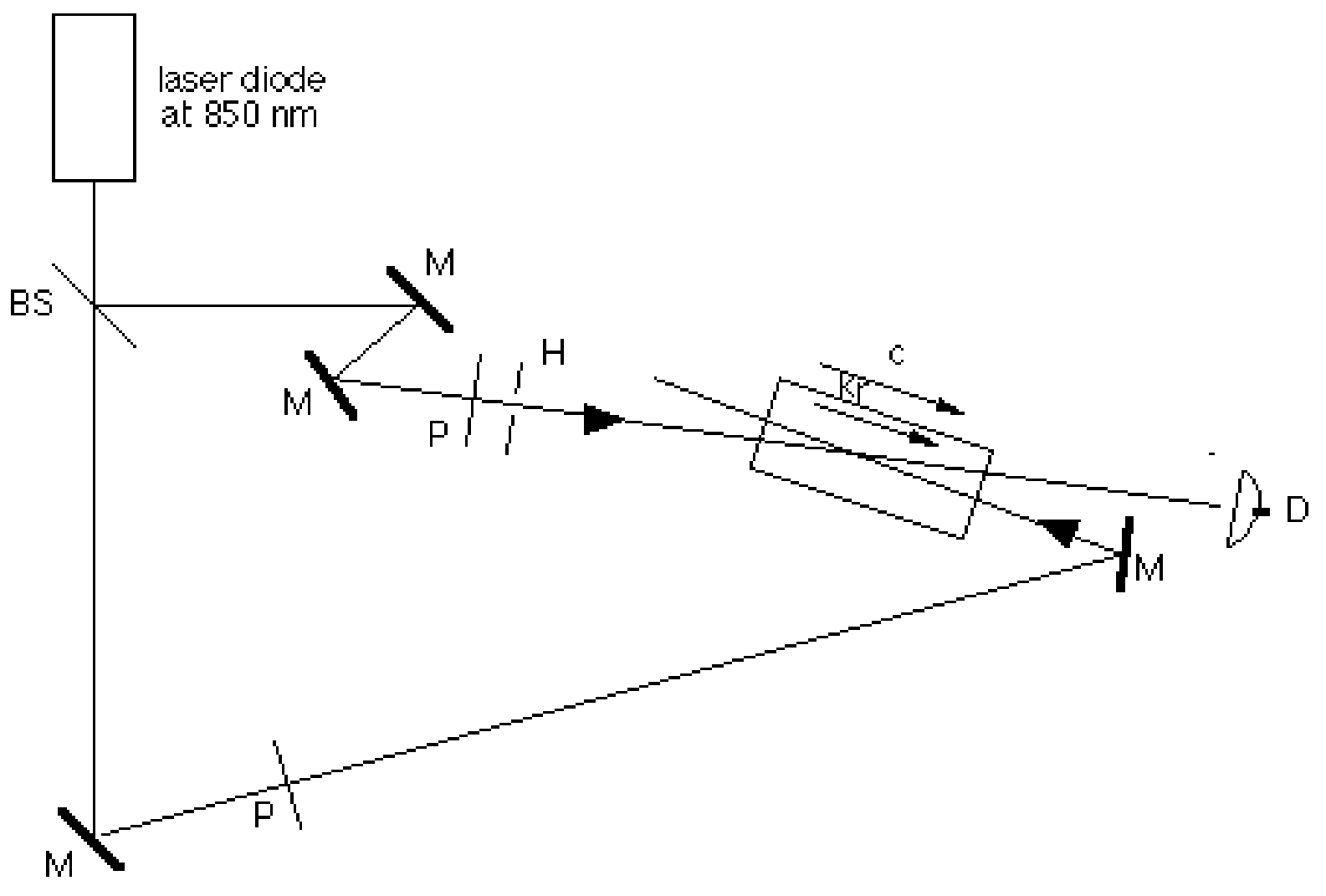

Figure 5 


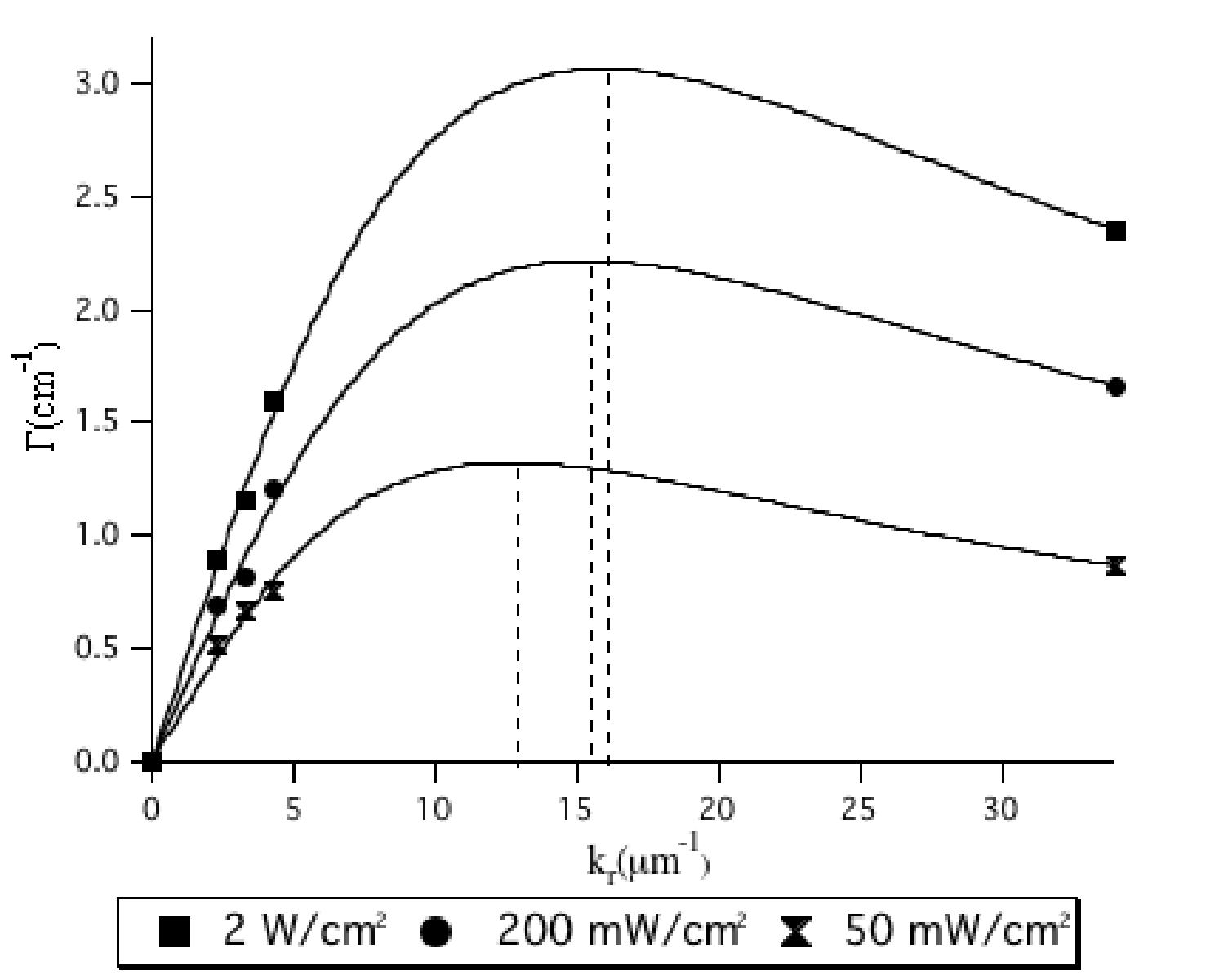

Figure 6 


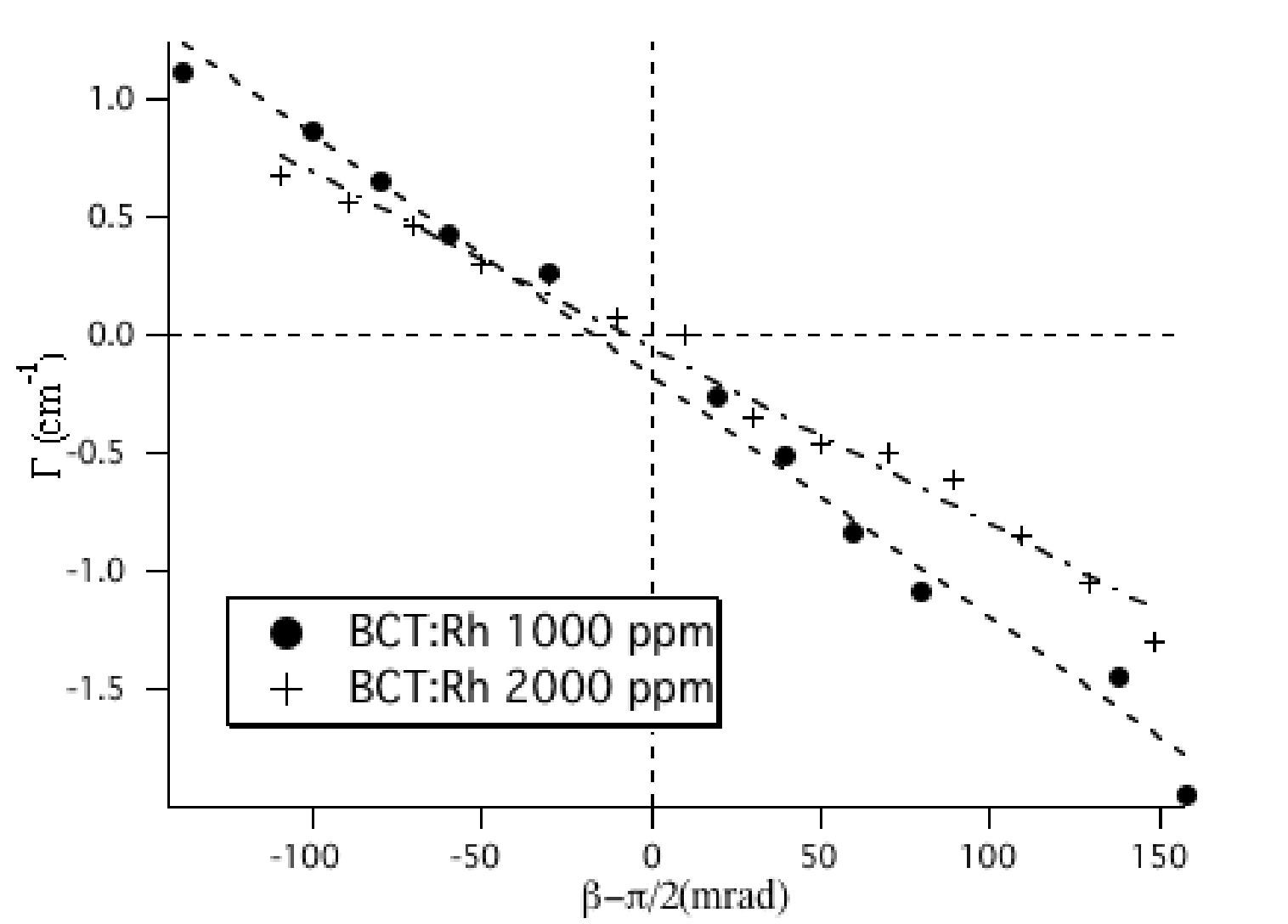

Figure 7 

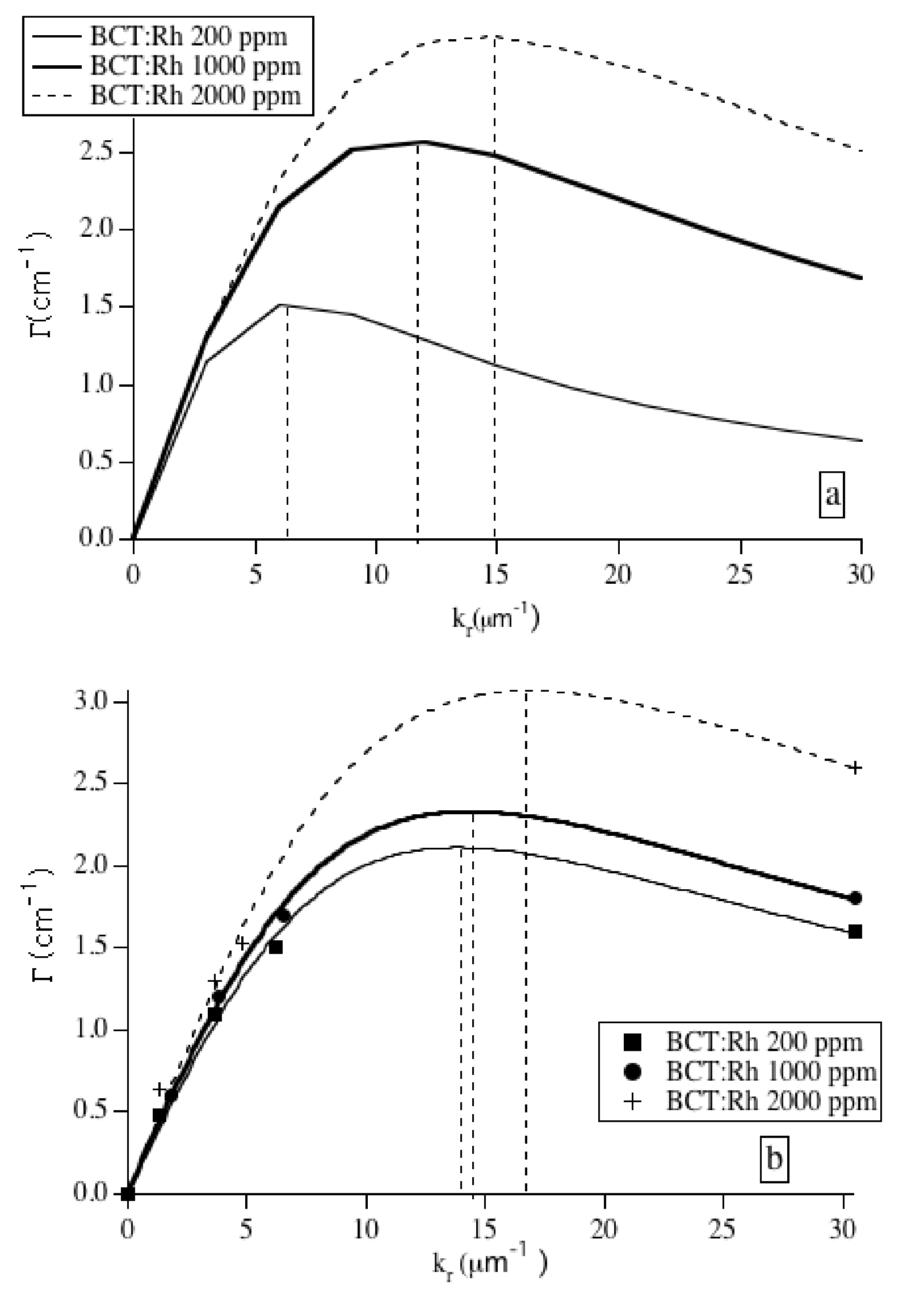

Figure 8 


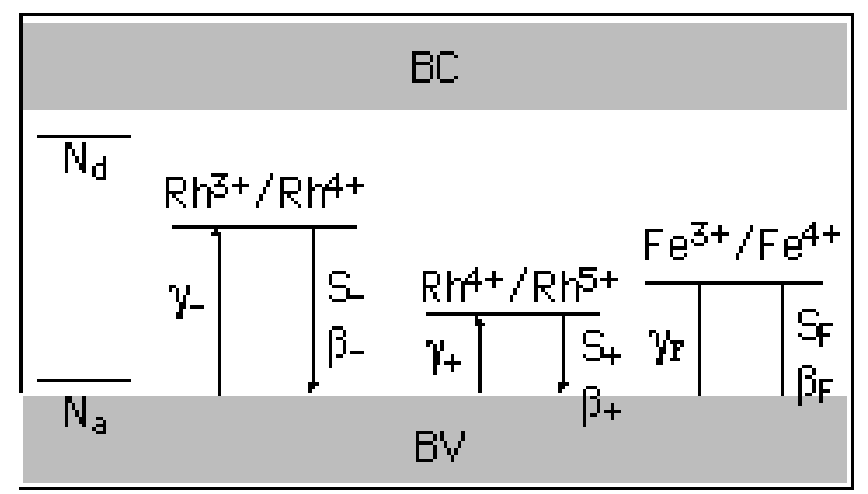

Figure 9 

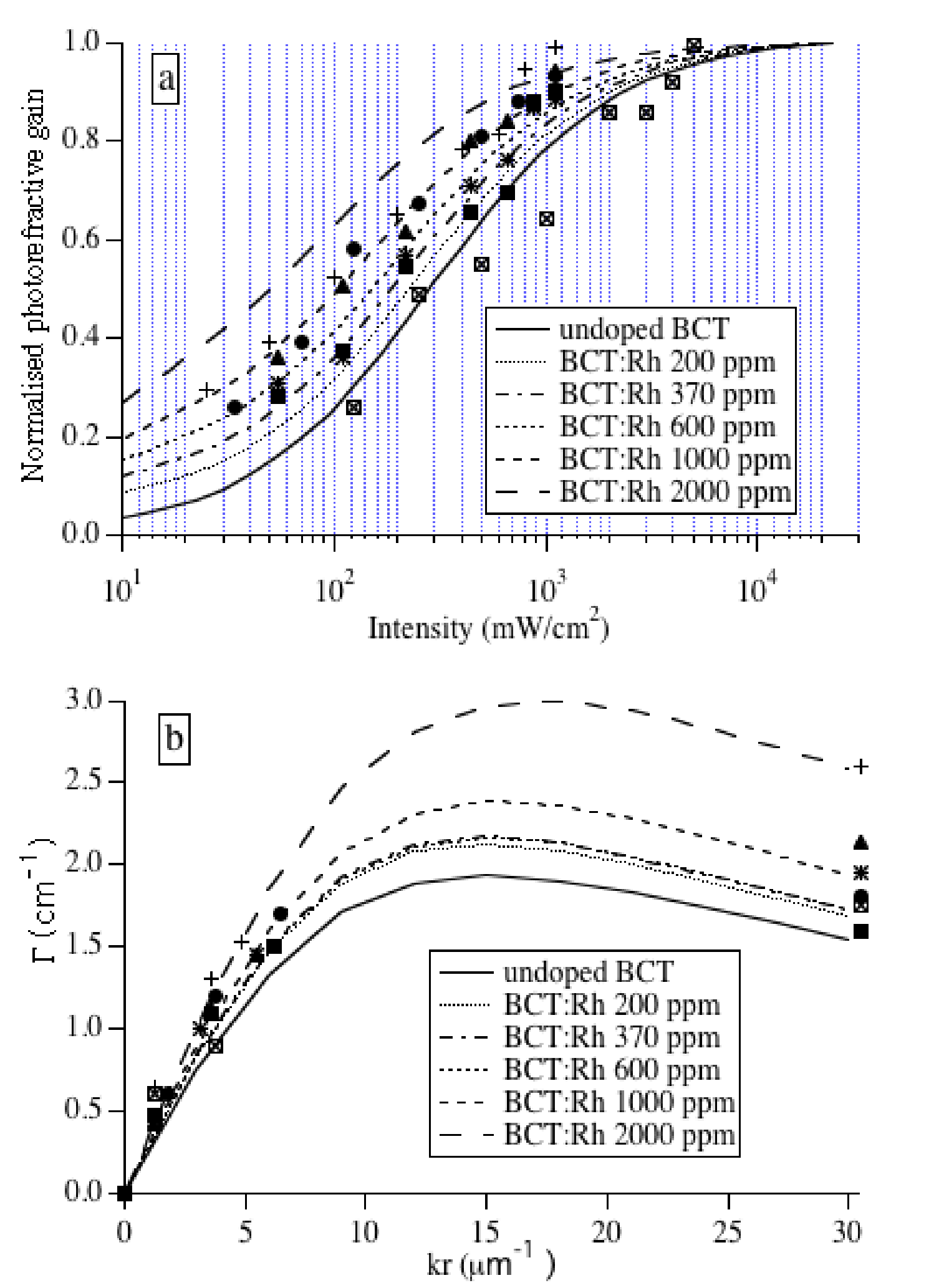

Figure 10 